\title{
Fluoxetine Administration Exacerbates Oral Tremor and Striatal Dopamine Depletion in a Rodent Pharmacological Model of Parkinsonism
}

\author{
Samantha J Podurgiel', Meredith N Milligan', Samantha E Yohn', Laura J Purcell', Hector M Contreras-Mora', \\ Mercè Correa ${ }^{2}$ and John D Salamone*,I \\ 'Department of Psychology, University of Connecticut, Storrs, CT, USA; ${ }^{2}$ Àrea de Psicobiologia, Universitat Jaume I, Castelló, Spain
}

\begin{abstract}
The cardinal motor symptoms of Parkinson's disease (PD) include resting tremor, akinesia, bradykinesia, and rigidity, and these motor abnormalities can be modeled in rodents by administration of the VMAT-2 (type-2 vesicular monoamine transporter) inhibitor tetrabenazine (9, I 0-dimethoxy-3-(2-methylpropyl)-I,3,4,6,7, I I b hexahydrobenzo[a]quinolizin-2-one; TBZ). Depression is also commonly associated with PD, and clinical data indicate that selective serotonin reuptake inhibitors (SSRIs) such as fluoxetine $(( \pm)-N$ methyl- $\boldsymbol{\gamma}$-[4-(trifluoromethyl)phenoxy]benzenepropanamine hydrochloride; FLX) are frequently used to treat depression in PD patients. The aim of the present study was to characterize the effect of FLX on the motor dysfunctions induced by a low dose of TBZ $(0.75 \mathrm{mg} / \mathrm{kg})$, and investigate the neural mechanisms involved. This low dose of TBZ was selected based on studies with rat models of depressive symptoms. In rats, coadministration of $F L X(2.5,5.0$, and $10.0 \mathrm{mg} / \mathrm{kg})$ increased TBZ-induced oral tremor (tremulous jaw movements),

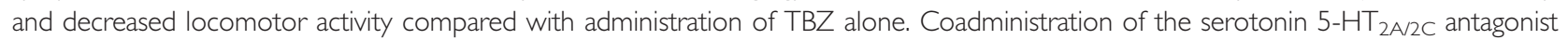
mianserin $(2.5$ and $5.0 \mathrm{mg} / \mathrm{kg}$ ) attenuated the increase in oral tremor induced by coadministration of TBZ $(0.75 \mathrm{mg} / \mathrm{kg})$ with $\mathrm{FLX}$ $(5.0 \mathrm{mg} / \mathrm{kg})$. Consistent with these behavioral data, coadministration of TBZ and FLX decreased DA tissue levels in the rat ventrolateral neostriatum compared with TBZ alone, and coadministration of mianserin with TBZ and FLX attenuated this effect, increasing DA tissue levels compared with the TBZ/FLX condition. These data suggest that SSRI administration in PD patients may result in

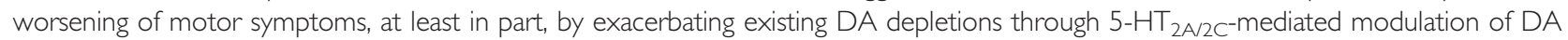
neurotransmission.

Neuropsychopharmacology (20I5) 40, 2240-2247; doi:I 0.1038/npp.20I5.69; published online 8 April 20I5
\end{abstract}

\section{INTRODUCTION}

Idiopathic Parkinson's disease (PD) is caused by a progressive degeneration of the dopamine (DA)-producing neurons of the substantia nigra pars compacta. In addition to idiopathic $\mathrm{PD}$, there also are drug-induced forms of Parkinsonism, which are caused by administration of drugs that block DA receptors or deplete DA. Parkinsonism is a family of motor disorders that is characterized by several cardinal motor symptoms, including resting tremor, akinesia, bradykinesia, and rigidity (Marsden et al, 1975; Ostrem and Galifianakis, 2010). These motor abnormalities can be modeled in rodents using various behavioral paradigms. Locomotor activity can be examined as an indicator of akinesia/bradykinesia, and the tremulous jaw movement (TJM) model can be used to evaluate resting tremor. TJMs

*Correspondence: Dr JD Salamone, Department of Psychology, University of Connecticut, 406 Babbidge Road, Storrs, CT 0626I1020, USA, Tel: + I 860486 4302, Fax: + I 860486 2760,

E-mail: john.salamone@uconn.edu

Received 29 October 2014; revised 15 January 2015; accepted 31 January 2015; accepted article preview online II March 2015 are defined as rapid vertical deflections of the lower jaw that resemble chewing but are not directed at any particular stimulus (Salamone et al, 1998) and are generated by conditions that parallel those that induce Parkinsonism in humans, including neurotoxic or pharmacological DA depletion, DA antagonism, and cholinomimetic administration (Jicha and Salamone, 1991; Salamone et al, 2008; Betz et al, 2009; Collins et al, 2011; Podurgiel et al, 2013). TJMs occur in the frequency range characteristic of Parkinsonian resting tremor (3-7.5 Hz; Salamone et al, 1998; Cousins et al, 1998; Collins et al, 2011; Podurgiel et al, 2013) and can be attenuated by administration of antiparkinsonian agents, including L-DOPA (Cousins et al, 1997), DA agonists (Cousins et al, 1997; Salamone et al, 2005), muscarinic antagonists (Cousins et al, 1997; Betz et al, 2009), and adenosine $\mathrm{A}_{2 \mathrm{~A}}$ antagonists (Correa et al, 2004; Simola et al, 2004; Tronci et al, 2007; Salamone et al, 2008; Betz et al, 2009; Collins et al, 2011, 2012; Podurgiel et al, 2013).

Although Parkinsonism is primarily characterized by the generation of the cardinal motor symptoms, patients with $\mathrm{PD}$ also suffer from a variety of significant non-motor symptoms, including autonomic dysfunction, sensory abnormalities, gastrointestinal issues, sleep disorders, and neuropsychiatric 
disturbances (Ostrem and Galifianakis, 2010; Barone, 2011). Neuropsychiatric symptoms are common even in the earliest stages of the disease, and can considerably affect the daily functioning and overall quality of life of PD patients (Aarsland et al, 2009; Barone, 2011). Depression, in particular, has been identified as the most significant predictor of health-related quality of life in PD (Schrag et al, 2000; Chen and Marsh, 2013), and systematic review and analysis suggest that $35-40 \%$ of patients with PD also experience clinically significant symptoms of depression (Slaughter et al, 2001; Aarsland et al, 2009).

Selective serotonin reuptake inhibitors (SSRIs) are prescribed more often than any other class of antidepressants for PD patients (Veazey et al, 2005; Aarsland et al, 2009; Chen and Marsh, 2013). Yet, controlled clinical trials, metaanalyses, and systematic review collectively suggest that SSRIs are no more effective than placebo in treating depression in the context of PD (Skapinakis et al, 2010; Aarsland et al, 2009). Furthermore, SSRI administration has been associated with a number of motor side effects, and may be implicated in increased motor disability in PD patients (Leo, 1996; Richard et al, 1997; Govoni et al, 2001; Veazey et al, 2005; Aarsland et al, 2009). There are presently more than 100 published reports of 'extrapyramidal' symptoms (eg dystonia, akathisia, dyskinesia, and Parkinsonism, including tremor) associated with SSRI treatment; fluoxetine (Prozac; ( \pm )- $N$-methyl- $\gamma$-[4(trifluoromethyl)phenoxy]benzenepropanamine hydrochloride; FLX) has been implicated in the majority of these reports (Madhusoodanan et al, 2010).

FLX primarily functions as an inhibitor of the serotonin (5-HT) transporter, preventing uptake of 5-HT and ultimately resulting in increased activation of a variety of 5-HT receptors, including the $5-\mathrm{HT}_{1 \mathrm{~A}}, 5-\mathrm{HT}_{2 \mathrm{~A}}$, and $5-\mathrm{HT}_{2 \mathrm{C}}$ receptors found throughout the striatum (Nutt et al, 1999; Alex and Pehek, 2007; More et al, 2014). Interactions between 5-HT and DA neurotransmission are strongly implicated in the generation of motor dysfunctions associated with FLX treatment (Morelli et al, 2011), as DA release and metabolite production are inhibited by increased synaptic levels of 5-HT (Govoni et al, 2001; Morelli et al, 2011). Activation of $5-\mathrm{HT}_{2 \mathrm{C}}$ receptors has been linked to decreased DA synthesis, neural activity, and release in the nigrostriatal and mesolimbic DA pathways (Alex and Pehek, 2007; More et al, 2014). In rodent models, FLX administration has been shown to potentiate haloperidol-induced catalepsy and bradykinesia in a dose-dependent manner (Tatara et al, 2012; More et al, 2014).

Thus, FLX treatment may result in increased motor deficits in PD patients because of 5-HT-mediated exacerbation of DA depletion and basal ganglia dysfunction. The present study sought to characterize this interaction using a pharmacological rodent model of Parkinsonism. Tetrabenazine (9,10-dimethoxy-3-(2-methylpropyl)-1,3,4,6,7, $11 b$ hexahydrobenzo[a]quinolizin-2-one; TBZ) is a reversible and selective inhibitor of the type-2 vesicular monoamine transporter (VMAT-2), which is used to treat chorea associated with Huntington's disease. Huntington's disease patients taking TBZ can experience adverse events, including Parkinsonian motor symptoms and depression (Kenney et al, 2007; Frank, 2009). Recent studies show that high doses of TBZ in rodents (eg, $2.0 \mathrm{mg} / \mathrm{kg}$ in rats, $5.0-10.0 \mathrm{mg} / \mathrm{kg}$ in CD1 mice) can induce TJMs and suppress locomotor activity
(Podurgiel et al, 2013). In the present studies, Experiment 1 examined the effect of acute administration of FLX (2.5, 5.0, or $10.0 \mathrm{mg} / \mathrm{kg}$ ) on TJMs and locomotor suppression induced by a low dose of TBZ $(0.75 \mathrm{mg} / \mathrm{kg})$ in rats; this low dose was selected because it is used to study rat models of the motivational symptoms of depression (Nunes et al, 2013; Randall et al, 2014). To test the hypothesis that $5-\mathrm{HT}_{2}$ family receptors are involved in the neural mechanisms underlying this behavior, experiment 2 assessed the ability of the $5-\mathrm{HT}_{2 \mathrm{~A} / 2 \mathrm{C}}$ antagonist mianserin to attenuate TJMs induced by coadministration of TBZ $(0.75 \mathrm{mg} / \mathrm{kg})$ and FLX $(5.0 \mathrm{mg} /$ $\mathrm{kg})$. Experiment 3 examined tissue levels of DA in the rat ventrolateral neostriatum (VLS), which is the homolog of the ventral putamen and the striatal subregion most closely associated with the production of TJMs (Jicha and Salamone, 1991; Salamone et al, 1998, 2008; Simola et al, 2004,Betz et al, 2009), after administration of TBZ $(0.75 \mathrm{mg} / \mathrm{kg})$, FLX $(5.0 \mathrm{mg} / \mathrm{kg})$, and mianserin $(5.0 \mathrm{mg} / \mathrm{kg})$.

\section{MATERIALS AND METHODS}

\section{Animals}

Adult male Sprague-Dawley rats $(N=34)$ weighing 350-450 g during the course of the experiment had ad libitum access to lab chow and water (Harlan Laboratories, Indianapolis, IN). They were pair-housed in a colony that was maintained at $\sim 23^{\circ} \mathrm{C}$ and had a $12 \mathrm{~h}$ light-dark cycle (lights on at 0700 hours). These studies were conducted according to the University of Connecticut and NIH guidelines for animal care and use.

\section{Pharmacological Agents and Selection of Doses}

TBZ, the VMAT-2 inhibitor, was purchased from Tocris Bioscience (Bristol, UK). TBZ was dissolved in a vehicle solution containing $0.9 \%$ of saline $(80 \%)$ and dimethylsulfoxide (DMSO) (20\%). Ten microliters of $\mathrm{HCl} / \mathrm{ml}$ volume was then added to get the drug completely in solution. FLX was purchased from Sigma-Aldrich Corporation (Saint Louis, MO). FLX was dissolved in $0.9 \%$ of saline. Mianserin hydrochloride $(1,2,3,4,10,14 \mathrm{~b}$-hexahydro-2-methyldibenzo[ $c$, $f]$ pyrazino[1,2-a]azepine hydrochloride) was purchased from Tocris Bioscience (Bristol, UK). Mianserin was dissolved in $0.3 \%$ of tartaric acid. A dose of $0.75 \mathrm{mg} / \mathrm{kg}$ TBZ was selected based on previous studies with animal models of the motivational symptoms of depression (Nunes et al, 2013; Randall et al, 2014), and also on studies showing that this dose was lower than those that produce substantial TJMs (Podurgiel et al., 2013), and was low enough to have a preferential effect on DA levels (Tanra et al., 1995). The doses of FLX used in experiment 1 (2.5, 5.0, and $10.0 \mathrm{mg} / \mathrm{kg}$ ) were selected based on extensive pilot work involving animal models of the motivational symptoms of depression (Yohn et al, unpublished data). Doses of FLX for experiment 2 were based on results from experiment 1. Doses of mianserin (2.5 and $5.0 \mathrm{mg} / \mathrm{kg}$ ) were selected based on previous work conducted in our laboratory (Carlson et al, 2003). 


\section{Tremulous Jaw Movements}

Observations of rats took place in a $30 \times 30 \times 30 \mathrm{~cm}^{3}$ clear Plexiglas chamber with a wire mesh floor, which was elevated $42 \mathrm{~cm}$ from the table top. This allowed for the viewing of the animal from several angles, including underneath. TJMs were defined as rapid vertical deflections of the lower jaw that resembled chewing but were not directed at any particular stimulus (Salamone et al, 1998). Each individual deflection of the jaw was recorded using a mechanical hand counter by a trained observer, who was blind to the experimental condition of the rat being observed. Separate studies with two observers demonstrated an inter-rater reliability of $r=0.999(p<0.01)$ using these methods.

\section{Locomotor Activity}

Locomotor activity was assessed by placing the rat in an automated activity chamber $\left(28 \times 28 \times 28 \mathrm{~cm}^{3}\right)$ enclosed in a sound-attenuating shell. The floor of the chamber was elevated $6 \mathrm{~cm}$ above the chamber bottom and was composed of two moveable wire mesh panels $\left(25 \times 12 \mathrm{~cm}^{2}\right)$ that were further divided into four quadrants by means of a central metal rod. As the rat entered each quadrant, a slight vertical movement of the mesh panels closed a microswitch located outside of the locomotion chamber. Each switch closure was detected and recorded by a computer program, written in MedPC (Med Associates, Georgia, VT), as a single activity count. The locomotor activity session was $18 \mathrm{~min}$ in length. These methods of measuring locomotion have been used previously to assess the effects of DA antagonists and TBZ on locomotion (Salamone et al, 2008; Podurgiel et al, 2013).

\section{Tissue Collection and HPLC}

Rats were exposed to carbon dioxide for $30 \mathrm{~s}$ and decapitated. Brains were quickly removed and frozen on a Leitz Wetzlar microtome. Coronal sections $750 \mu \mathrm{m}$ thick were cut through the VLS. A 16-gauge stainless-steel tube was used to dissect bilateral cylindrical samples from the VLS. The VLS was selected because of a substantial literature showing that this site is the most critical striatal subregion involved in the regulation of TJMs. Several papers have included placement controls, including injections into multiple striatal sites, multiple drugs or lesion methods, and injections into control sites dorsal to the VLS (Kelley et al., 1989; Salamone et al., 1990; Jicha and Salamone, 1991; Cousins et al., 1998; Simola et al., 2004). As previous work has shown that DA depletions could induce TJMs when 6-OHDA was injected into the VLS, but not other striatal sites (Jicha and Salamone, 1991), it was decided that the VLS was the critical neostriatal locus upon which to focus for studies involving DA tissue levels. These tissue samples were then placed in $200 \mu \mathrm{l}$ of $0.1 \mathrm{~N}$ perchloric acid, and then homogenized, centrifuged, and frozen. The supernatant was subsequently analyzed using high-performance liquid chromatography with electrochemical detection (HPLC-EC; ESA Coulochem II system). The electrochemical parameters were as follows: channel $1=-100 \mathrm{mV}$, channel $2=+200 \mathrm{mV}$, and guard cell $=+350 \mathrm{mV}$. Each liter of mobile phase contained $27.6 \mathrm{~g}$ sodium phosphate monobasic, $8.0 \%$ of methanol,
$750 \mu \mathrm{l}$ of $0.1 \mathrm{M}$ EDTA, and $2875 \mu \mathrm{l}$ of $0.4 \mathrm{M}$ sodium octyl sulfate dissolved in deionized ultrapure $\mathrm{H}_{2} \mathrm{O}$ with a final $\mathrm{pH}$ of 4.5 . The flow rate was $1.0 \mathrm{ml} / \mathrm{min}$.

\section{Experiments}

Experiment 1: Ability of FLX to exacerbate TBZ-induced TJMs and locomotor suppression. A group of 12 rats was used to assess the effects of the acute administration of FLX on the motor symptoms induced by $0.75 \mathrm{mg} / \mathrm{kg}$ TBZ. A within-groups design was used for this study, with all rats receiving all drug treatments in a randomly varied order (one treatment per 3 week block; no treatment sequences repeated). On the test day, which occurred once every 3 weeks, each rat received an intraperitoneal injection of either $1.0 \mathrm{ml} / \mathrm{kg}$ vehicle solution ( $80 \%$ saline, $20 \%$ DMSO) or $0.75 \mathrm{mg} / \mathrm{kg}$ TBZ. Thirty minutes later, rats received an intraperitoneal injection of either $1.0 \mathrm{ml} / \mathrm{kg} 0.9 \%$ saline (vehicle) or 2.5, 5.0, or $10.0 \mathrm{mg} / \mathrm{kg}$ FLX. Thus, there were six conditions being studied (vehicle/vehicle (Veh/Veh), TBZ/vehicle (TBZ/Veh), vehicle $/ 10.0 \mathrm{mg} / \mathrm{kg}$ FLX (Veh/FLX), and TBZ with either 2.5, 5.0 , or $10.0 \mathrm{mg} / \mathrm{kg}$ FLX). One hour and twenty minutes after the second injection, rats were placed in the Plexiglas observation chamber and allowed to habituate for $10 \mathrm{~min}$. TJMs were then counted for $15 \mathrm{~min}$, with the observation period divided into three 5-min epochs. Upon completion of the TJM assessment, locomotor activity was assessed in the same group of 12 rats in an 18-min session using the procedure outlined above.

Experiment 2: Ability of mianserin to attenuate TJMs induced by coadministration of TBZ and FLX. A group of eight rats was used to assess the ability of the $5-\mathrm{HT}_{2 \mathrm{~A} / 2 \mathrm{C}}$ antagonist mianserin to attenuate TJMs induced by the acute coadministration of TBZ $(0.75 \mathrm{mg} / \mathrm{kg})$ and FLX $(5.0 \mathrm{mg} / \mathrm{kg})$. A within-groups design was used, with all rats receiving all drug treatments in a randomly varied order (one treatment per 3-week block; no treatment sequences repeated). On the test day, which occurred once every 3 weeks, each rat received an intraperitoneal injection of either $1.0 \mathrm{ml} / \mathrm{kg}$ vehicle solution ( $80 \%$ saline, $20 \%$ DMSO) or $0.75 \mathrm{mg} / \mathrm{kg}$ TBZ. Thirty minutes later, rats received an intraperitoneal injection of either $1.0 \mathrm{ml} / \mathrm{kg} 0.9 \%$ saline (vehicle) or 2.5, 5.0, or $10.0 \mathrm{mg} / \mathrm{kg}$ FLX. Fifty minutes later, rats received a subcutaneous injection of either $1.0 \mathrm{ml} / \mathrm{kg} 0.3 \%$ tartaric acid (vehicle) or 2.5 or $5.0 \mathrm{mg} / \mathrm{kg}$ mianserin. Thirty minutes after the third injection, rats were placed in the Plexiglas observation chamber and allowed to habituate for $10 \mathrm{~min}$. TJMs were then counted for $15 \mathrm{~min}$, with the observation period divided into three 5-min epochs.

Experiment 3: Neurochemical analyses for tissue DA after administration of TBZ, FLX, and mianserin. A total of 34 rats were used to examine tissue levels of DA after administration of TBZ, FLX, and mianserin (the 12 rats from experiment 1 , the 8 rats from experiment 2 , and 14 additional rats that received drug treatments matching those of the animals used for the first two experiments; these additional animals were needed because the tissue assay experiments required a larger total $N$ because of the betweengroups design). A between-groups design was used for this 


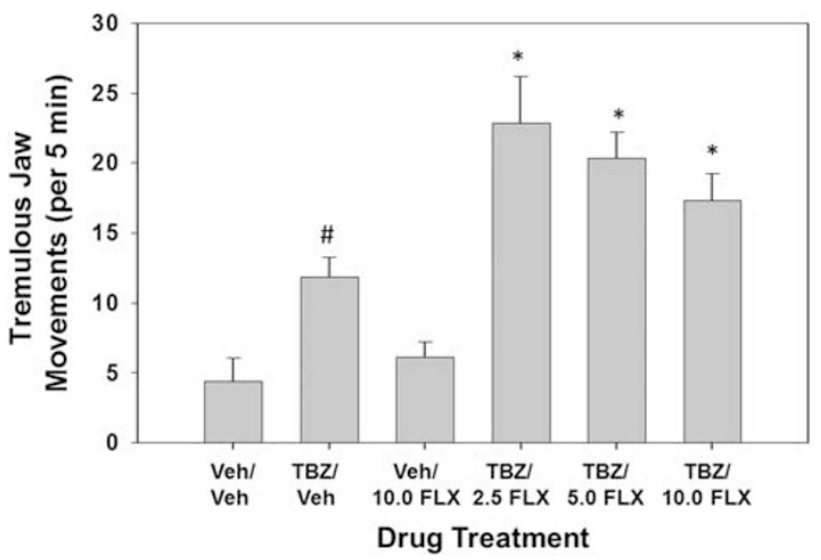

Figure I Mean $( \pm \mathrm{SEM})$ number of tremulous jaw movements (TJMs) per $5 \mathrm{~min}$ observation period in rats that received injections of vehicle (Veh/Neh), $0.75 \mathrm{mg} / \mathrm{kg}$ tetrabenazine (TBZNeh), or various $\mathrm{mg} / \mathrm{kg}$ doses of fluoxetine (FLX; $2.5-10.0 \mathrm{mg} / \mathrm{kg}$ ) in combination with TBZ. "Different from Veh/Veh, $p<0.05$; *TBZ/FLX different from TBZNVeh, $p<0.05$

study, with rats being randomly assigned to one of four treatment conditions: Veh/Veh/Veh $(n=9)$, TBZ/Veh/Veh $(n=9)$, TBZ/FLX/Veh $(n=8)$, or TBZ/FLX/mianserin $(n=8)$. Rats received an intraperitoneal injection of either $1.0 \mathrm{ml} / \mathrm{kg}$ vehicle solution ( $80 \%$ saline, $20 \% \mathrm{DMSO}$ ) or $0.75 \mathrm{mg} / \mathrm{kg} \mathrm{TBZ}$. Thirty minutes later, rats received an intraperitoneal injection of either $1.0 \mathrm{ml} / \mathrm{kg} 0.9 \%$ saline (vehicle) or $5.0 \mathrm{mg} / \mathrm{kg}$ FLX. Fifty minutes later, rats received a subcutaneous injection of either $1.0 \mathrm{ml} / \mathrm{kg} 0.3 \%$ tartaric acid (vehicle) or $5.0 \mathrm{mg} / \mathrm{kg}$ mianserin. Forty minutes later, tissue collection was performed. One week later, samples were analyzed for DA content using HPLC-EC as described above.

\section{Data Analysis}

The data for experiments 1 and 2 were analyzed using a repeated-measures analysis of variance (ANOVA). Average TJMs per 5-min observation period were calculated and used in the ANOVA calculations. A computerized statistical program (SPSS 21.0 for Windows) was used to perform these analyses. When there was a significant ANOVA, planned comparisons using the overall error term were used to assess the differences between each dose and the control condition (Keppel, 1991; the number of comparisons was restricted to the number of treatments minus one). For experiment 3, DA levels were expressed as nanogram $/ \mathrm{mg}$ wet weight of tissue. Data were analyzed using a between-groups ANOVA. When there was a significant ANOVA, planned comparisons using the error term from the paired conditions were used to assess the differences between conditions.

\section{RESULTS}

Experiment 1: Ability of FLX to Exacerbate TBZ-Induced TJMs and Locomotor Suppression

Repeated-measures ANOVA revealed a significant overall treatment effect on TJMs (Figure 1; $\mathrm{F}(5,55)=19.307$;

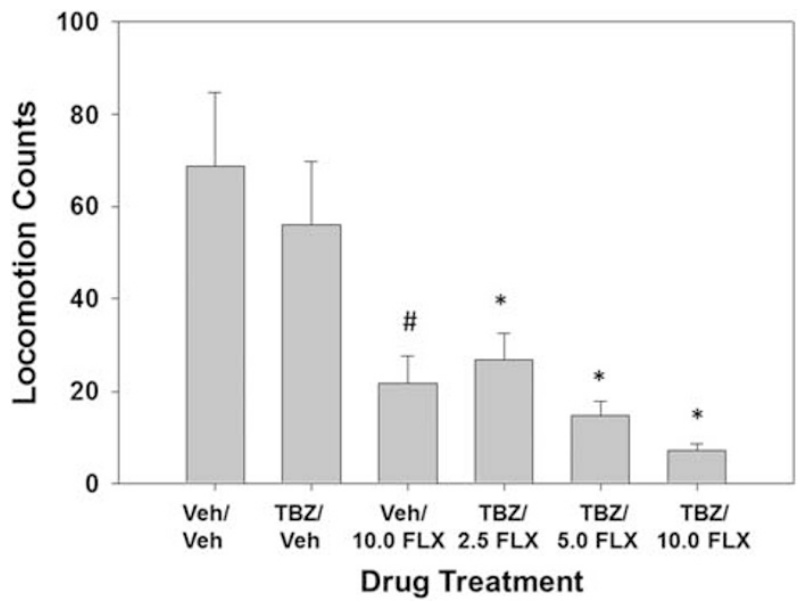

Figure 2 Mean $( \pm$ SEM) number of locomotor activity counts in rats that received injections of vehicle (Veh/Neh), $0.75 \mathrm{mg} / \mathrm{kg}$ tetrabenazine (TBZ/ Veh), or various $\mathrm{mg} / \mathrm{kg}$ doses of fluoxetine ( $F L X ; 2.5-10.0 \mathrm{mg} / \mathrm{kg}$ ) in combination with TBZ. "Different from Veh/Veh, $p<0.05$; *TBZ/FLX different from TBZNeh, $p<0.05$.

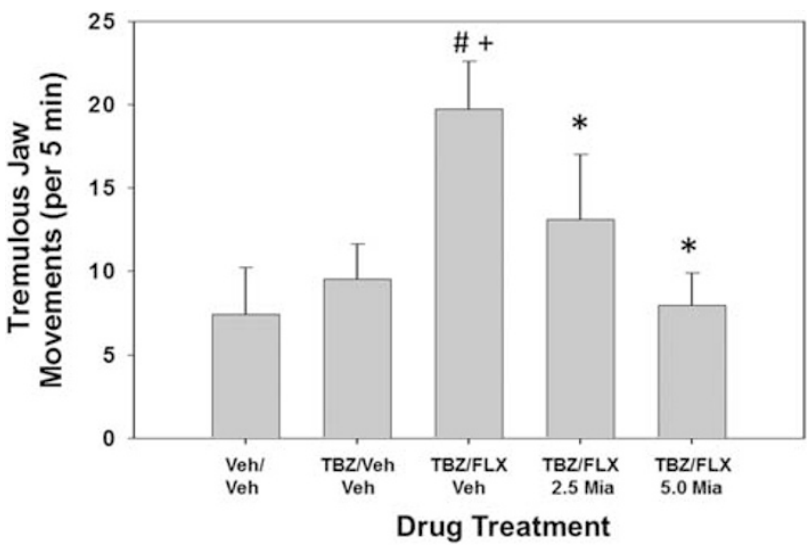

Figure 3 Mean $( \pm$ SEM) number of tremulous jaw movements (TJMs) per 5 min observation period in rats that received injections of vehicle (Veh/ Veh), $0.75 \mathrm{mg} / \mathrm{kg}$ tetrabenazine (TBZNeh), $5.0 \mathrm{mg} / \mathrm{kg}$ fluoxetine (FLX), and various doses of mianserin (Mia; $2.5-5.0 \mathrm{mg} / \mathrm{kg}$ ) in combination with TBZ and FLX. ${ }^{\#}$ Different from Veh/Neh, $p<0.05 ;{ }^{*} T B Z / F L X / V e h$ different from TBZNeh/Veh, $p<0.05$; *TBZ/FLX/Mia different from TBZ/FLXNeh, $p<0.05$.

$p<0.05)$. The $0.75 \mathrm{mg} / \mathrm{kg}$ dose of TBZ significantly induced TJMs compared with vehicle controls (planned comparisons, $p<0.05)$. Coadministration of TBZ $(0.75 \mathrm{mg} / \mathrm{kg})$ with 2.5 , 5.0 , or $10.0 \mathrm{mg} / \mathrm{kg}$ doses of FLX significantly increased TJMs from TBZ alone (planned comparisons, $p<0.05$ ). Repeatedmeasures ANOVA also revealed a significant overall treatment effect for locomotion (Figure 2; $\mathrm{F}(5,55)=6.757$; $p<0.05$ ). The $10.0 \mathrm{mg} / \mathrm{kg}$ dose of FLX significantly suppressed locomotor activity as compared with vehicle controls (planned comparisons, $p<0.05$ ). Coadministration of $0.75 \mathrm{mg} / \mathrm{kg}$ TBZ and 2.5, 5.0, or $10.0 \mathrm{mg} / \mathrm{kg}$ doses of FLX significantly reduced locomotor activity compared with TBZ alone (planned comparisons, $p<0.05$ ). 


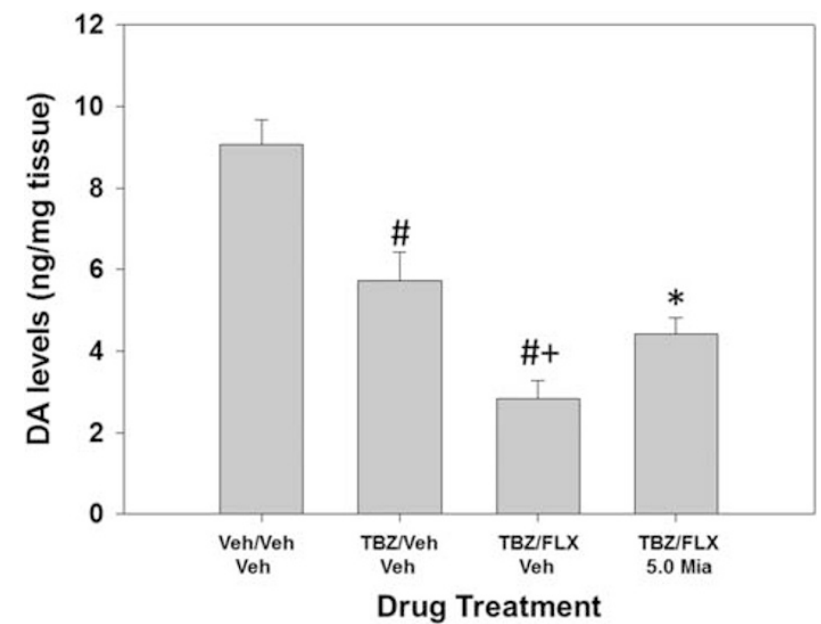

Figure 4 Mean $( \pm$ SEM) amount of DA in ventrolateral neostriatum (ng/ $\mathrm{mg}$ tissue) in rats that received injections of vehicle (Veh/Veh), $0.75 \mathrm{mg} / \mathrm{kg}$ tetrabenazine (TBZNeh), $5.0 \mathrm{mg} / \mathrm{kg}$ fluoxetine (FLX), and $5.0 \mathrm{mg} / \mathrm{kg}$ mianserin (Mia) in combination with TBZ and FLX. \#Different from Veh/ Veh, $p<0.05$; ${ }^{+} \mathrm{TBZ} / \mathrm{FL} X N$ Veh different from TBZNeh/Veh, $p<0.05$; *TBZ/ FLX/Mia different from TBZ/FLXNeh, $p<0.05$.

\section{Experiment 2: Ability of Mianserin to Attenuate TJMs Induced by Coadministration of TBZ and FLX}

Repeated-measures ANOVA revealed a significant overall treatment effect on TJMs (Figure 3; F $(4,28)=3.451 ; p<0.05$ ). Coadministration of $0.75 \mathrm{mg} / \mathrm{kg} \mathrm{TBZ}$ and $5.0 \mathrm{mg} / \mathrm{kg}$ FLX significantly increased TJMs from the vehicle condition (planned comparisons, $p<0.05$ ) and TBZ alone (planned comparisons, $p<0.05)$. Both doses of mianserin $(2.5$ and $5.0 \mathrm{mg} / \mathrm{kg}$ ) significantly reduced TJMs induced by coadministration of TBZ $(0.75 \mathrm{mg} / \mathrm{kg})$ and FLX $(5.0 \mathrm{mg} / \mathrm{kg})$ (planned comparisons, $p<0.05)$.

\section{Experiment 3: Neurochemical Analyses for Tissue DA Levels after Administration of TBZ, FLX, and Mianserin}

Between-subjects ANOVA revealed a significant overall treatment effect on DA levels in the VLS $(F(3,30)=21.489$; $p<0.0001$; Figure 4). Administration of TBZ $(0.75 \mathrm{mg} / \mathrm{kg})$ decreased DA levels in the VLS compared with the vehicle condition $(\mathrm{F}(1,16)=4.49 ; p<0.05)$. Coadministration of TBZ $(0.75 \mathrm{mg} / \mathrm{kg})$ and FLX $(5.0 \mathrm{mg} / \mathrm{kg})$ further decreased DA levels in the VLS compared with TBZ alone $(\mathrm{F}(1,15)=4.54 ; p<0.05)$. Coadministration of mianserin $(5.0 \mathrm{mg} / \mathrm{kg})$ with TBZ $(0.75 \mathrm{mg} / \mathrm{kg})$ and FLX $(5.0 \mathrm{mg} / \mathrm{kg})$ increased DA levels compared with TBZ and FLX alone $(\mathrm{F}(1,14)=4.60 ; p<0.05)$.

\section{DISCUSSION}

The present studies were undertaken to characterize the effects of the antidepressant FLX on motor dysfunctions, particularly the oral tremor marked by TJMs, which are induced by the VMAT-2 inhibitor TBZ. These drugs were selected because Huntington's disease patients prescribed TBZ for the treatment of chorea may experience Parkinsonism and depression as adverse events (Kenney et al, 2007;
Frank, 2009; Guay, 2010), and also because SSRIs such as FLX are frequently used to treat depression associated with Parkinsonism (Veazey et al, 2005; Aarsland et al, 2009; Chen and Marsh, 2013; Schreiber and Thompson, 2013). Administration of high doses of TBZ (eg, $2.0 \mathrm{mg} / \mathrm{kg}$ ) in rats has been used as a pharmacological rodent model of Parkinsonism (Podurgiel et al, 2013), whereas lower doses such as $0.75 \mathrm{mg} / \mathrm{kg}$ are used to model motivational symptoms of depression (Nunes et al, 2013; Randall et al, 2014). Experiment 1 showed that a low dose of TBZ $(0.75 \mathrm{mg} / \mathrm{kg})$ produced a small but significant increase in TJMs compared with the vehicle condition, and this effect of TBZ was markedly enhanced by coadministration of FLX $(2.5,5.0$, or $10.0 \mathrm{mg} / \mathrm{kg}$ ), which significantly increased TJMs compared with TBZ alone. Additionally, administration of FLX $(10.0 \mathrm{mg} / \mathrm{kg})$ significantly decreased locomotion compared with vehicle control, and coadministration of TBZ $(0.75 \mathrm{mg} / \mathrm{kg})$ plus FLX $(2.5,5.0$, and $10.0 \mathrm{mg} / \mathrm{kg})$ significantly decreased locomotion compared with TBZ alone. Thus, results from experiment 1 showed that FLX administration exacerbates Parkinsonian-like motor dysfunctions induced by a low dose of TBZ in rats. These results are consistent with studies showing potentiation of haloperidol-induced motor impairments (eg, catalepsy and bradykinesia) by FLX in rodents (Tatara et $a l, 2012$ ), and with numerous clinical reports linking motor side effects and worsening Parkinsonism with FLX treatment of depression (Leo, 1996; Gerber and Lynd, 1998; Govoni et al, 2001; Madhusoodanan et al, 2010).

Previous research has demonstrated that $5-\mathrm{HT}$ is involved in the modulation of drug and lesion-induced TJMs. Stewart et al (1987) reported that pilocarpine-induced vacuous chewing-like movements were reduced by coadministration of para-chlorophenylalanine, which blocks 5-HT synthesis and depletes central 5-HT stores. Evidence also indicates that $5-\mathrm{HT}_{2}$ family receptors are involved in the regulation of TJM activity. Atypical antipsychotic drugs that act as $5-\mathrm{HT}_{2}$ family antagonists or inverse agonists generally fail to induce TJMs and, in fact, can suppress the TJMs induced by cholinomimetic drugs (Salamone et al, 1998; Betz et al, 2005, 2009). Furthermore, the $5-\mathrm{HT}_{2 \mathrm{~A} / 2 \mathrm{C}}$ receptor antagonist mianserin was shown to suppress the TJMs induced by the 5-HT agonists $m$-chlorophenylpiperazine and quipazine (Stewart et al, 1989), as well as an anticholinesterase tacrine (Carlson et $a l, 2003)$. In view of these previous findings, experiment 2 investigated the ability of mianserin to attenuate the TJMs induced by coadministration of TBZ $(0.75 \mathrm{mg} / \mathrm{kg})$ and FLX $(5.0 \mathrm{mg} / \mathrm{kg})$. The results showed that administration of mianserin $(2.5$ and $5.0 \mathrm{mg} / \mathrm{kg})$ significantly reduced the number of TJMs induced by coadministration of TBZ and FLX, thereby indicating that FLX exacerbates TJMs via activation of $5-\mathrm{HT}_{2 \mathrm{~A}}$ and/or $5-\mathrm{HT}_{2 \mathrm{C}}$ receptors. Although mianserin is nonselective for different subtypes of $5-\mathrm{HT}_{2}$ receptors, previous work has shown that the rank order of potency for the suppression of tacrine-induced TJMs by atypical antipsychotics is related to their affinity for $5-\mathrm{HT}_{2 \mathrm{~A}}$ receptors (Betz et al, 2005), and also that the selective $5-\mathrm{HT}_{2 \mathrm{~A}}$ inverse agonist ACP-103 could reduce tacrine-induced TJMs (Vanover et al., 2008). Future studies should investigate the effects of selective antagonists or inverse agonists of $5-\mathrm{HT}_{2 \mathrm{~A}}$ and $5-\mathrm{HT}_{2 \mathrm{C}}$ receptors on the FLX-induced enhancement of tetrabenazine-induced TJMs.

Previous research has shown that the VLS is the neostriatal region most closely associated with the production of TJMs 
(Kelley et al, 1989; Salamone et al, 1990, 1998, 2008; Jicha and Salamone, 1991; Betz et al, 2009), and that DA depletion in the VLS, but not other striatal subregions, induces TJMs in rats (Jicha and Salamone, 1991). Therefore, to determine if changes in striatal DA levels are related to the pattern of behavioral effects observed in experiments 1 and 2, experiment 3 examined DA tissue levels in the VLS of rats after administration of TBZ $(0.75 \mathrm{mg} / \mathrm{kg})$, FLX $(5.0 \mathrm{mg} / \mathrm{kg})$, and mianserin $(5.0 \mathrm{mg} / \mathrm{kg})$. As predicted, TBZ administration decreased DA tissue levels in the VLS compared with the vehicle condition. Consistent with the pattern of effects observed in the behavioral experiments, coadministration of TBZ and FLX further decreased DA tissue levels compared with TBZ alone, and mianserin attenuated this effect, with coadministration of mianserin in combination with TBZ and FLX increasing DA tissue levels compared with the TBZ/FLX condition.

The precise mechanisms through which FLX enhances the TJMs induced by TBZ is not clear. Although one cannot completely discount the possibility of specific pharmacodynamic or pharmacokinetic interactions between these two particular drugs, it is important to emphasize that motor dysfunctions induced by FLX or other 5-HT uptake inhibitors have been reported to occur in humans and other animals under conditions in which a variety of other drugs were being administered, and even when no other drugs were being given. Furthermore, the ability of mianserin to reduce TJMs has been observed under a variety of conditions, including cases in which either a 5-HT agonist (Stewart et al, 1989) or an anticholinesterase (Carlson et al, 2003) was being administered. The present results are consistent with a substantial literature demonstrating serotonergic modulation of TJMs across a broad array of pharmacological conditions (Stewart et al, 1987, 1989; Salamone et al, 1998; Carlson et al, 2003; Betz et al, 2005 Vanover et al, 2008). Serotonergic neurons from the raphe nucleus project to the dopaminergic midbrain nuclei (substantia nigra pars compacta and ventral tegmental area), as well as to their target structures, the striatum and nucleus accumbens (Michelsen et al, 2007). The 5- $\mathrm{HT}_{2}$ receptor family, with particular emphasis on the $5-\mathrm{HT}_{2 \mathrm{~A}}$ and $5-\mathrm{HT}_{2 \mathrm{C}}$ receptor subtypes, has been implicated in serotonergic modulation of mesolimbic and nigrostriatal DA activity (Di Giovanni et al, 1999; Di Matteo et al, 2000; Porras et al, 2002; Alex et al, 2005; Alex and Pehek, 2007), although it is unclear how these physiological interactions are related to the present findings. Prototypical SSRIs like FLX block uptake of 5-HT from the synapse by inhibiting the 5-HT transporter, resulting in increased synaptic levels of 5-HT and increased activation of 5-HT receptors (Nutt et al, 1999). Furthermore, FLX treatment has been shown to reduce levels of DA and its metabolite in the neostriatum of mice (Morelli et al, 2011). Based on the present results, it is reasonable to hypothesize that FLX administration may be enhancing the TJMs induced by TBZ by reducing DA tissue levels in VLS, an effect that is mediated via increased stimulation of $5-\mathrm{HT}_{2 \mathrm{~A}}$ and/or $5-\mathrm{HT}_{2 \mathrm{C}}$ receptors. Nevertheless, interactions involving other brain areas (eg, substantia nigra) and neurotransmitters (eg, acetylcholine) may also be important.

Overall, the results from this study indicate that acute FLX administration exacerbates drug-induced Parkinsonism in a pharmacological rodent model, possibly due to increased stimulation of $5-\mathrm{HT}_{2 \mathrm{~A}}$ and/or $5-\mathrm{HT}_{2 \mathrm{C}}$ receptors. As antidepressant drugs are typically given chronically, future studies should also examine the effects of long-term administration of FLX and other SSRIs. These results have significant implications for understanding the movementrelated adverse events, including tremor, which are induced by FLX (Brambilla et al, 2005; Madhusoodanan et al, 2010), and the complications that may result from the continued use of FLX in patients with idiopathic or drug-induced Parkinsonism, particularly in view of evidence suggesting that SSRIs may be no more effective than placebo in treating PD related to depression (Skapinakis et al, 2010; Aarsland et al, 2009).

\section{FUNDING AND DISCLOSURE}

This research was supported by grants from NIH/NIMH, the University of Connecticut Research Foundation, and the Psychology Department Undergraduate Research Grant program. HC received an NSF Bridge to the Doctorate grant, and SP received a Parkinson's Disease Foundation grant. JS has received grants from, and done consulting work for, Pfizer, Roche, Shire, and Prexa, and SY was supported by grants from Shire and Prexa. MC received a grant from Fundació Bancaixa/U Jaume I (P1.1B2010-43). The authors declare no conflict of interest.

\section{ACKNOWLEDGMENTS}

We wish to thank Tiahna Spencer for her assistance.

\section{REFERENCES}

Aarsland D, Marsh L, Schrag A (2009). Neuropsychiatric symptoms in Parkinson's disease. Mov Disor 24: 2175-2186.

Alex KD, Pehek EA (2007). Pharmacologic mechanisms of serotonergic regulation of dopamine neurotransmission. Pharmacol Ther 113: 296-320.

Alex KD, Yavanian GJ, McFarlane HG, Pluto CP, Pehek EA (2005). Modulation of dopamine release by striatal 5-HT2C receptors. Synapse 55: 242-251.

Barone P (2011). Treatment of depressive symptoms in Parkinson's disease. Eur J Neurol 18(Suppl 1): 11-15.

Betz A, Ishiwari K, Wisniecki A, Huyn N, Salamone JD (2005). Quetiapine (Seroquel) shows a pattern of behavioral effects similar to the atypical antipsychotics clozapine and olanzapine: studies with tremulous jaw movements in rats. Psychopharmacology 179: 383-392.

Betz AJ, Vontell R, Valenta J, Worden L, Sink KS, Font L et al (2009). Effects of adenosine A2A antagonist KW-6002 (istradefylline) on pimozide-induced oral tremor and striatal c-Fos expression: comparisons with the muscarinic antagonist tropicamide. Neuroscience 163: 97-108.

Brambilla P, Cipriani A, Hotopf M, Barbui C (2005). Side-effect profile of fluoxetine in comparison with other SSRIs, tricyclic and newer antidepressants: a meta-analysis of clinical trial data. Pharmacopsychiatry 38: 69-77.

Carlson BB, Wisniecki A, Salamone JD (2003). Local injections of the 5-hydroxytryptamine antagonist mianserin into substantia nigra pars reticulata block tremulous jaw movements in rats: studies with a putative model of Parkinsonian tremor. Psychopharmacology 165: 229-237.

Collins LE, Paul NE, Abbas SF, Leser CE, Podurgiel SJ, Galtieri DJ et al (2011). Oral tremor induced by galantamine in rats: a model 
of the parkinsonian side effects of cholinomimetics used to treat Alzheimer's disease. Pharmacol Biochem Behav 99: 414-422.

Collins LE, Sager TN, Sams AG, Pennarola A, Port RG, Shahriari $\mathrm{M}$ et al (2012). The novel adenosine A2A antagonist Lu AA47070 reverses the motor and motivational effects produced by dopamine D2 receptor blockade. Pharmacol Biochem Behav 100: 498-505.

Correa M, Wisniecki A, Betz A, Dobson DR, O’Neill MF, O’Neill MJ et al (2004). The adenosine A2A antagonist KF17837 reverses locomotor suppression and tremulous jaw movements induced by haloperidol in rats: possible relevance to parkinsonism. Behav Brain Res 148: 47-54.

Cousins MS, Carriero DL, Salamone JD (1997). Tremulous jaw movements induced by the acetylcholinesterase inhibitor tacrine: effects of antiparkinsonian drugs. Eur J Pharmacol 322: 137-145.

Cousins MS, Atherton A, Salamone JD (1998). Behavioral and electromyographic characterization of the local frequency of tacrine-induced tremulous jaw movements. Physiol Behav 64: 153-158.

Chen JJ, Marsh L (2013). Depression in Parkinson's disease: identification and management. Pharmacotherapy 33: 972-983.

Di Matteo V, Di Giovanni G, Di Mascio M, Esposito E (2000). Biochemical and electrophysiological evidence that RO 60-0175 inhibits mesolimbic dopaminergic function through serotonin (2C) receptors. Brain Res 865: 85-90.

Di Giovanni G, De Deurwaerdére P, Di Mascio M, Di Matteo V, Esposito E, Spampinato U (1999). Selective blockade of serotonin$2 \mathrm{C} / 2 \mathrm{~B}$ receptors enhances mesolimbic and mesostriatal dopaminergic function: a combined in vivo electrophysiological and microdialysis study. Neuroscience 91: 587-597.

Frank S (2009). Tetrabenazine as anti-chorea therapy in Huntington disease: an open-label continuation study. Neurol 9: 62 .

Gerber PE, Lynd LD (1998). Selective serotonin-reuptake inhibitorinduced movement disorders. Ann Pharmacother 32: 692-698.

Govoni S, Racchi M, Masoero E, Zamboni M, Ferini-Strambi L (2001). Extrapyramidal symptoms and antidepressant drugs: neuropharmacological aspects of a frequent interaction in the elderly. Mol Psychiatr 6: 134-142.

Guay DR (2010). Tetrabenazine, a monoamine-depleting drug used in the treatment of hyperkinectic movement disorders. Am J Geriatr Pharmacother 8: 331-373.

Jicha GA, Salamone JD (1991). Vacuous jaw movements and feeding deficits in rats with ventrolateral striatal dopamine depletion: possible relation to parkinsonian symptoms. J Neurosci 11: 3822-3829.

Kelley AE, Bakshi VP, Delfs JM, Lang CG (1989). Cholinergic stimulation of the ventrolateral striatum elicits mouth movements in rats: pharmacological and regional specificity. Psychopharmacology 99: 542-549.

Kenney C, Hunter C, Jankovic J (2007). Long-term tolerability of tetrabenazine in the treatment of hyperkinetic movement disorders. Mov Disord 22: 193-197.

Keppel G (1991). Design and Analysis: A Researcher's Handbook3rd edn.Prentice Hall: Upper Saddle River, NJ.

Leo RJ (1996). Movement disorders associated with the serotonin selective reuptake inhibitors. J Clin Psychiatry 57: 449-454.

Madhusoodanan S, Alexeenko L, Sanders R, Brenner R (2010). Extrapyramidal symptoms associated with antidepressants-a review of the literature and an analysis of spontaneous reports. Ann Clin Psychiatry 22: 148-156.

Marsden CD, Duvoisin RC, Jenner P, Parkes JD, Pycock C, Tarsy D (1975). Relationship between animal models and clinical Parkinsonism. Adv Neurol 9: 165-175.

Michelsen KA, Schmitz C, Steinbusch HW (2007). The dorsal raphe nucleus - from silver stainings to a role in depression. Brain Res Rev 55: 329-342.

More K, Thorat VM, Shinde AR, Balsara JJ (2014). Effect of antidepressant fluoxetine a SSRI on dopamine dependent behaviors in rats. Res Rev; J Pharmacol Toxicol Stud 2: 29-38.
Morelli E, Moore H, Rebello TJ, Gray N, Steele K, Esposito E et al (2011). Chronic 5-HT transporter blockage reduces DA signaling to elicit basal ganglia dysfunction. J Neurosci 31: 15742-15750.

Nunes EJ, Randall PA, Hart EE, Freeland C, Yohn SE, Baqi Y et al (2013). Effort-related motivational effects of the VMAT-2 inhibitor tetrabenazine: implications for animal models of the motivational symptoms of depression. J Neurosci 33: 19120-19130.

Nutt DJ, Forshall S, Bell C, Rich A, Sandford J, Nash J et al (1999). Mechanisms of action of selective serotonin reuptake inhibitors in the treatment of psychiatric disorders. Eur Neuropsychopharmacol 9(Suppl 3): S81-S86.

Ostrem JL, Galifianakis NB (2010). Overview of common movement disorders. Continuum Lifelong Learn Neurol 16: 13-48.

Podurgiel SJ, Nunes EJ, Yohn SE, Barber J, Thompson A, Milligan M et al (2013). The vesicular monoamine transporter (VMAT-2) inhibitor tetrabenazine induces tremulous jaw movements in rodents: implications for pharmacological models of parkinsonian tremor. Neuroscience 250: 507-519.

Porras G, Di Matteo V, Fracasso C, Lucas G, De Deurwaerdère P, Caccia et al (2002). 5-HT2A and 5-HT2C/2B receptor subtypes modulate dopamine release induced in vivo by amphetamine and morphine in both the rat nucleus accumbens and striatum. Neuropsychopharmacology 26: 311-324.

Randall PA, Lee CA, Nunes EJ, Yohn SE, Nowak V et al (2014). The VMAT-2 inhibitor tetrabenazine affects effort-related decision making in a progressive ratio/chow feeding choice task: reversal with antidepressant drugs. PLoS One 9: e99320.

Richard IH, Kurlan RParkinson Study Group (1997). A survey of antidepressant drug use in Parkinson's disease. Neurology 49: $1168-1170$

Salamone JD, Johnson CJ, McCullough LD, Steinpreis RE (1990). Lateral striatal cholinergic mechanisms involved in oral motor activities in the rat. Psychopharmacology 102: 529-534.

Salamone JD, Mayorga AJ, Trevitt JT, Cousins MS, Conlan A, Nawab A (1998). Tremulous jaw movements in rats: a model of parkinsonian tremor. Progr Neurobiol 56: 591-611.

Salamone JD, Carlson BB, Rios C, Lentini E, Correa M, Wisniecki A et al (2005). Dopamine agonists suppress cholinomimeticinduced tremulous jaw movements in an animal model of parkinsonism: tremerolytic effects of pergolide, ropinirole, and CY 208-243. Behav Brain Res 156: 173-179.

Salamone JD, Betz AJ, Ishiwari K, Felsted J, Madson L, Mirante B et al (2008). Tremorolytic effects of adenosine A2A antagonists: implications for parkinsonism. Front Biosci 13: 3594-3605.

Schrag A, Jahanshahi M, Quinn N (2000). What contributes to quality of life in patients with Parkinson's disease? J Neurol Neurosurg Psychiatry 69: 308-312.

Schreiber MA, Thompson AW (2013). The pharmacologic management of depression in Parkinson's disease. Degen Neurol Neuromusc Dis 3: 1-9.

Simola N, Fenu S, Baraldi PG, Tabrizi MA, Morelli M (2004). Blockade of adenosine $\mathrm{A} 2 \mathrm{~A}$ receptors antagonizes parkinsonian tremor in the rat tacrine model by an action on specific striatal regions. Exp Neurol 189: 182-188.

Skapinakis P, Bakola E, Salanti G, Lewis G, Kyritsis AP, Mavreas V (2010). Efficacy and acceptability of selective serotonin reuptake inhibitors for the treatment of depression in Parkinson's disease: a systematic review and meta-analysis of randomized controlled trials. BMC Neurol 10: 49.

Slaughter JR, Slaughter KA, Nichols D, Holmes SE, Martens MP (2001). Prevalence, clinical manifestations, etiology, and treatment of depression in Parkinson's Disease. J Neuropsychiatry Clin Neurosci 13: 187-196.

Stewart BR, Rose S, Jenner P, Marsden CD (1987). Pilocarpineinduced purposeless chewing behaviour in rats is dependent on intact central stores of 5-HT. Eur J Pharmacol 142: 173-176. 
Stewart BR, Jenner P, Marsden CD (1989). Induction of purposeless chewing behavior in rats by 5 -HT agonist drugs. Eur J Pharmacol 162: 101-107.

Tanra AJ, Kagaya A, Okamoto Y, Muraoka M, Motohashi N, Yamawaki S (1995). TJS-010, a new prescription of oriental medicine, antagonizes tetrabenazine-induced suppression of spontaneous locomotor activity in rats. Prog Neuropsychopharmacol Biol Psychiatry 19: 963-971.

Tatara A, Shimizu S, Shin N, Sato M, Sugiuchi T, Imaki J et al (2012). Modulation of antipsychotic-induced extrapyramidal side effects by medications for mood disorders. Prog Neuro-Psychoph 38: $252-259$.
Tronci E, Simola N, Borsini F, Schintu N, Frau L, Carminati P et al (2007). Characterization of the antiparkinsonian effects of the new adenosine A2A receptor antagonist ST1535: acute and subchronic studies in rats. Eur J Pharmacol 566: 94-102.

Vanover KE, Betz AJ, Weber SM, Bibbiani F, Kielaite A, Weiner DM et al (2008). A 5-HT2A receptor inverse agonist, ACP-103, reduces tremor in a rat model and levodopa-induced dyskinesias in a monkey model. Pharmacol Biochem Behav 90: 540-544.

Veazey C, Erden SO, Cook KF, Lai EC, Kunick ME (2005). Prevalence and treatment of depression in Parkinson's disease. J Neuropsychiatry Clin Neurosci 17: 310-323. 